\title{
Similitude law for shallow foundation on cohesionless soils using 2D finite element analysis
}

\author{
Myungjae Lee ${ }^{\text {i) }}$, Kyung-tae Bae ${ }^{\text {ii) }}$, Hong Taek Kim ${ }^{\text {iii) }}$, Seung-Cheol Baek ${ }^{\text {iv) }}$ and Heejung Youn ${ }^{\text {v)* }}$
}

i) Ph.D. Student, Department of Civil Engineering, Hongik University, Sangsu-dong, Mapo-gu, Seoul, Republic of Korea

ii) Senior Researcher, Daewoo Institute of Construction Technology, Songjuk-dong, Jangan-gu, Suwon, Gyeonggi-do, Republic of Korea

iii) Professor, Department of Civil Engineering, Hongik University, Sangsu-dong, Mapo-gu, Seoul, Republic of Korea

iv) Professor, Department of Civil Engineering, Andong National University, Andong-si, Gyeongsangbuk-do, Republic of Korea

v) Assistant Professor, Department of Civil Engineering, Hongik University, Sangsu-dong, Mapo-gu, Seoul, Republic of Korea,

Corresponding author (geotech@hongik.ac.kr)

\begin{abstract}
This paper investigated the similitude law for strip footing resting on cohesionless soils. 2D finite element analyses were employed to estimate the ultimate unit bearing pressure of strip footing in three different conditions: laboratory model test under 1-g, centrifuge test under n-g, and full scale test under 1-g. The Hardening Soil model was used for cohesionless soil to account for the increase in shear strength and stiffness with depth. Based on the numerical results, the axial unit bearing pressure-settlement curves were collected. The ultimate unit bearing pressures and settlements for three simulations were compared, and stress scale ratio and geometric scale ratio were drawn such that ultimate unit bearing pressure in full scale test could be estimated from laboratory test results.
\end{abstract}

Keywords: strip footing, similitude law, scaling relation, unit bearing pressure, 2D finite element

\section{INTRODUCTION}

For estimating the bearing capacity of shallow foundation in cohesionless soils, laboratory model test has been carried out for its simplicity and easiness to handle. However, the shear strength of cohesionless soils is highly dependent on the confining pressure, which increases with depth, and the results obtained from laboratory model test are very difficult to interpret. The geometric scale ratio, $n$, which is the ratio between length in full scale model and laboratory scale model, can be used to extrapolate the model test results to full scale test results. The correlation between model and full scale test is called as similitude law.

Model tests include n-g centrifuge test and 1-g model test depending on the gravity condition in use. Centrifuge test simulates increasing confining pressure with depth by applying n-times the gravity, and the test results are known to well represent the full scale test. However, the correlation between the 1-g model test and full scale test is not as simple as the centrifuge test. Ko (1988) proposed the scaling relations among full scale test, centrifuge test, and laboratory model test as shown in Table 1. He employed geometric scale ratio, $n$, and stress scale ratio, $N$, which can be calculated from void ratio. Even though he derived the scaling relations, his finding lacks verification from real test data or numerical analyses.

In this paper, strip footing was selected for deriving scaling relation between $1-\mathrm{g}$ laboratory model test and full scale test using 2D finite element method. Commercial software, PLAXIS, was used to create laboratory scale model and full scale model. The strip footing with laboratory scale model was axially loaded to failure under two gravity condition: $1-\mathrm{g}\left(9.81 \mathrm{~m} / \mathrm{s}^{2}\right)$ and $20-g\left(196.2 \mathrm{~m} / \mathrm{s}^{2}\right)$. The latter case represents the centrifuge test. The strip footing in full scale, whose size is 20 times the laboratory scale, was also axially loaded to failure to calculate the bearing capacity.

Table 1 Scaling relations (Modified from Ko (1988))

\begin{tabular}{cccc}
\hline & $\begin{array}{c}\text { Full scale } \\
\text { model }\end{array}$ & $\begin{array}{c}\text { Centrifuge } \\
\text { model at equal } \\
\text { stress level }\end{array}$ & $\begin{array}{c}\text { Laboratory } \\
\text { model }\end{array}$ \\
\hline Length & 1 & $n$ & $n$ \\
\hline Area & 1 & $n^{2}$ & $n^{2}$ \\
\hline Volume & 1 & $n^{3}$ & $n^{3}$ \\
\hline Mass & 1 & $n^{3}$ & $\mathrm{~N} / \mathrm{A}$ \\
\hline Acceleration & 1 & $1 / n$ & $1 / n$ \\
\hline Stress & 1 & 1 & 1 \\
\hline Strain & 1 & 1 & $n$ \\
\hline Displacement & 1 & $n$ & $N n^{2}$ \\
\hline Force & 1 & $n^{2}$ & $e_{m}=e_{p}+\lambda \ln (N)$ \\
\hline Void ratio & 1 & $\mathrm{~N} / \mathrm{A}$
\end{tabular}

$n$ :geometric scale ratio

$N$ : stress scale ratio

N/A: not available

\section{NUMERICAL MODEL}

In order to calibrate the PLAXIS model, the load-settlement curve of strip footing in laboratory 
scale was obtained from previous research (Mandal and Manjunath, 1995). Unfortunately, it is impossible to obtain the load-settlement curve of full scale test. Fig. 1 shows the side view of laboratory testing set-up from the literature. The soil container was $610 \mathrm{~mm}$ long and $460 \mathrm{~mm}$ high, and the width of strip footing was set to $100 \mathrm{~mm}$. Similarly, PLAXIS model was created with the same dimensions as shown in Fig. 2. Mesh was refined near the bottom of strip footing. The numerical model is in plain strain condition, and 15-node triangular element was adopted. The bottom boundary of the model was fixed in both horizontal and vertical direction, and both sides of the model were fixed in horizontal direction. For constitutive model, the Hardening Soil model was selected to simulate pressure dependent behavior of sands. In the model, the shear strength of sand increases with depth as the confining pressure increases with depth. In addition, the increase in elastic modulus can be simulated by adjusting fitting parameter, $m$.

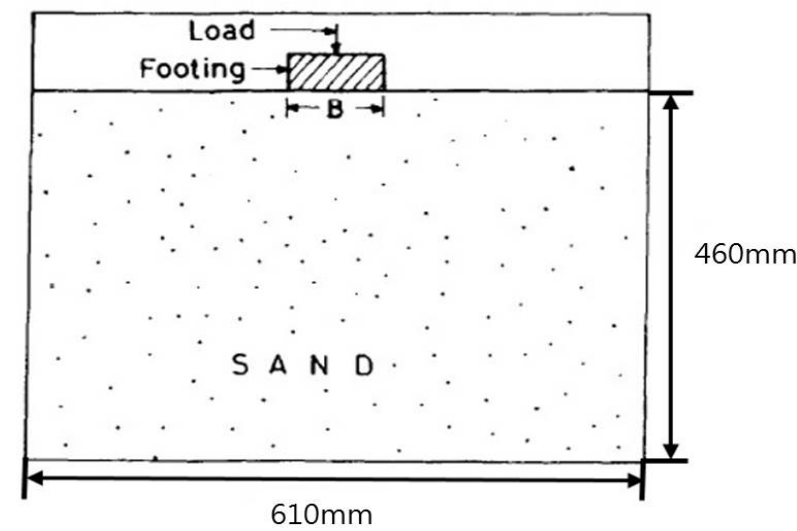

Fig. 1 Side view of laboratory scale experiment on strip footing (Mandal and Manjunath, 1995)

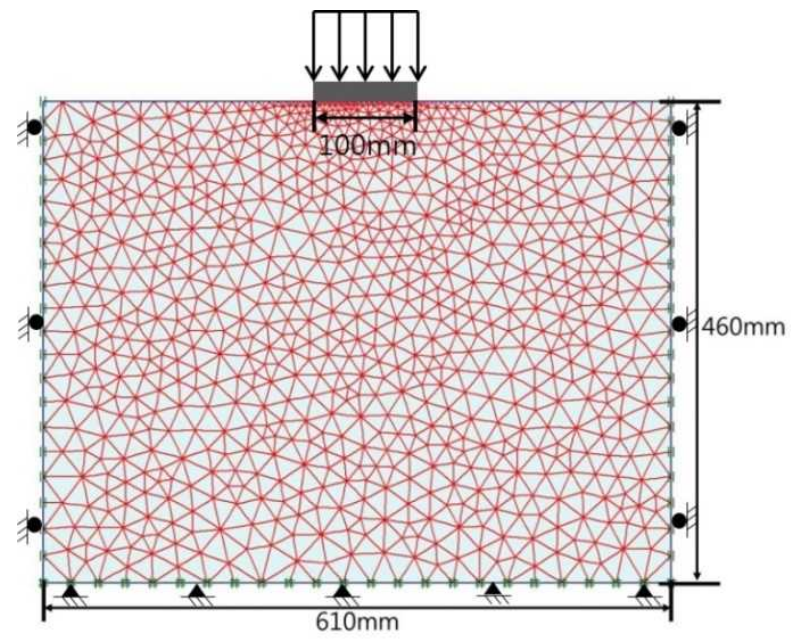

Fig. 2 Mesh generation and boundary condition in the PLAXIS model

Table 2 tabulates the material properties used in the laboratory test, and the input parameters into PLAXIS analysis. The dilation angle was assumed to be $8^{\circ}$, which is recommended value from PLAXIS manual (Brinkgreve, 2002). The reference elastic modulus parameter, $E_{50}^{r e f}$, and the fitting parameter, $m$, was back-calculated using the load-settlement curve from laboratory model test (Fig. 3). The reference elastic modulus was back-calculated to be $7,500 \mathrm{kPa}$, and the fitting parameter was 0.8 after trial-and-error calibration. As shown in Fig. 3, the settlement of numerical analysis agrees well with the laboratory test, but the ultimate bearing pressure was estimated slightly higher in the numerical analysis than laboratory test. Hence, the ultimate unit bearing pressure of strip footing was estimated using proposed equation by Meyerhof (1951) and Terzaghi (1943), and the results were plotted in the Fig. 3. The numerical analysis and experiment appear to provide reasonable estimate.

Table 2. Material parameters of 1-g laboratory test and input parameters for the Hardening Soil model

\begin{tabular}{ccc}
\hline & $\begin{array}{c}\text { Laboratory } \\
\text { test }\end{array}$ & $\begin{array}{c}\text { Numerical } \\
\text { analysis }\end{array}$ \\
\hline Type of soil & Sand & Sand \\
\hline Dry unit weight $\left(\mathrm{kN} / \mathrm{m}^{3}\right)$ & 18.1 & 18.1 \\
\hline Relative density $(\%)$ & 73 & - \\
\hline Friction angle $\left(^{\circ}\right)$ & 38 & 38 \\
\hline Dilation angle $\left(^{\circ}\right)$ & - & 8 \\
\hline Specific gravity, $\mathrm{G}_{\mathrm{s}}$ & 2.65 & - \\
\hline Effective grain size, $\mathrm{D}_{10}(\mathrm{~mm})$ & 0.2 & - \\
\hline Coefficient of uniformity, $\mathrm{C}_{\mathrm{u}}$ & 4.6 & - \\
\hline$E_{50}^{\text {ref }}(\mathrm{kPa})$ & - & 7,500 \\
\hline$m$ & - & 0.8 \\
\hline
\end{tabular}

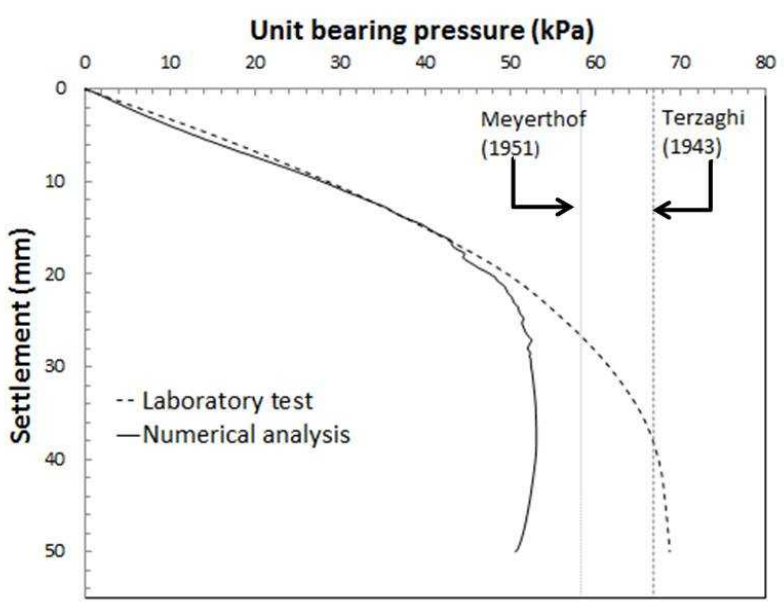

Fig. 3 unit bearing pressure - settlement curve obtained from 1-g laboratory test and numerical analysis

Table 3 provides information of three numerical analyses carried out in this study: 1) laboratory test with $100 \mathrm{~mm}$ footing width and $1 \mathrm{-g}$ condition, 2) centrifuge 
test with $100 \mathrm{~mm}$ footing width and 20 -g condition, and 3) full scale test with $2,000 \mathrm{~mm}$ width and 1-g condition. The geometric scale ratio is 20 in this study.

Table 3 Dimensions and gravity used in the numerical analyses

\begin{tabular}{cccc}
\hline Test type & $\begin{array}{c}\text { Footing } \\
\text { width }(\mathrm{mm})\end{array}$ & $\begin{array}{c}\text { Soil container } \\
(\mathrm{W} \times \mathrm{L}, \mathrm{mm})\end{array}$ & $\begin{array}{c}\text { Gravity } \\
(\mathrm{g})\end{array}$ \\
\hline Laboratory test & 100 & $610 \times 410$ & 1 \\
\hline Centrifuge test & 100 & $610 \times 410$ & 20 \\
\hline Full scale test & 2,000 & $12,200 \times 8,200$ & 1 \\
\hline
\end{tabular}

\section{NUMERICAL RESULTS}

Table 4 presents the peak load and ultimate unit bearing pressure obtained from three different types of tests. The ultimate unit bearing pressure of strip footing was calculated by averaging vertical stress at the bottom of the footing. Without applying scaling relation, the ultimate unit bearing pressures were calculated to be 53.1, 862.0, and $902.8 \mathrm{kPa}$, respectively. Similarly, the peak load was estimated by averaging peak load at three representing nodes. It should be noted that the peak load is not calculated for unit length $(1 \mathrm{~m})$ but for the footing width. Scaling relation shown in the Table 1 was applied to the bearing pressure - settlement curves for comparison between 1) centrifuge test and full scale test, and 2) laboratory test and full scale test.

Table 4 Calculated unit bearing pressure and peak load

\begin{tabular}{crr}
\hline Test type & $\begin{array}{c}\text { Ultimate unit bearing } \\
\text { pressure }(\mathrm{kPa})\end{array}$ & \multicolumn{2}{c}{$\begin{array}{c}\text { Peak load } \\
(\mathrm{kN})\end{array}$} \\
\hline Laboratory test & 53.1 & 0.5 \\
\hline Centrifuge test & 862.0 & 7.9 \\
\hline Full scale test & 902.8 & $3,166.9$ \\
\hline
\end{tabular}

\subsection{Centrifuge test vs. full scale test}

Fig. 4 displays the unit bearing pressure-settlement curves of strip footing for centrifuge test and full scale test after applying scaling factor. According to Table 1 , the stress in centrifuge model is identical to the stress in full scale test, which is clearly proven through numerical results. The settlement was adjusted by applying 20 for the geometric scale ratio, $n$. The discrepancy in ultimate unit bearing pressure was found to be $4.7 \%$, and that in settlement appeared to be negligible (see Table 5). The peak load for centrifuge test was converted to full scale test by multiplying $\mathrm{n}^{2}$ (400) to $7.9 \mathrm{kN}$, resulting in merely $0.4 \%$ discrepancy in the peak load.

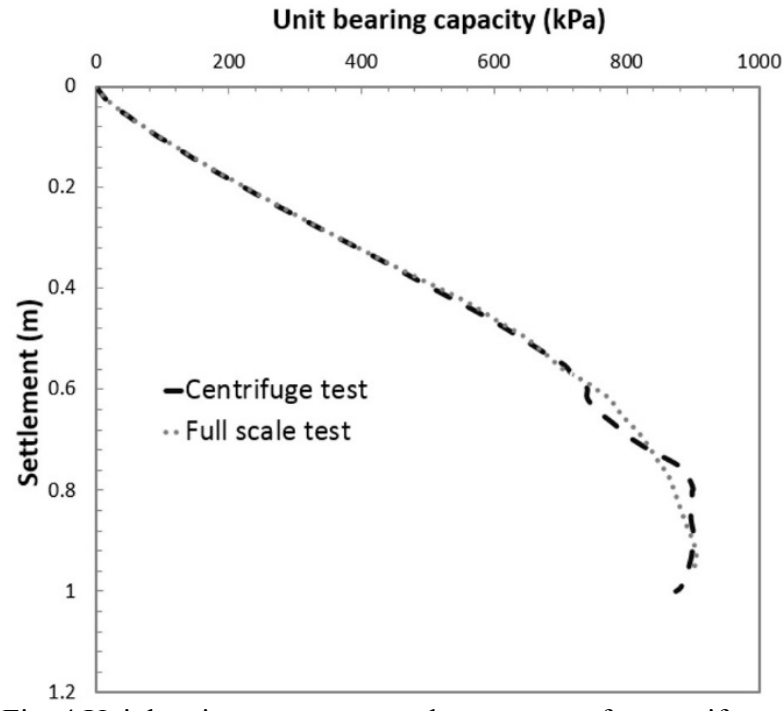

Fig. 4 Unit bearing pressure - settlement curve for centrifuge test and full scale test

Table 5 Comparison of centrifuge test and full scale test

\begin{tabular}{crcr}
\hline & $\begin{array}{c}\text { Centrifu } \\
\text { ge test }\end{array}$ & $\begin{array}{c}\text { Full scale } \\
\text { test }\end{array}$ & $\begin{array}{c}\text { Discrepa } \\
\text { ncy }(\%)\end{array}$ \\
\hline $\begin{array}{c}\text { Ultimate unit bearing } \\
\text { pressure }(\mathrm{kPa})\end{array}$ & 862.0 & 902.8 & 4.7 \\
\hline Peak load $(\mathrm{kN})$ & 3153.0 & 3166.9 & 0.4 \\
\hline
\end{tabular}

\subsection{Laboratory scale test vs. full scale test}

Even though centrifuge test has been proven for its validity numerically and experimentally, scaling relation between laboratory model test and full scale test has not been thoroughly investigated. The geometric scale ratio, $n$, is 20 and simple to calculate; the stress scale ratio, $N$, is a function of void ratio (see Table 1). Thus, the stress scale ratio was back-calculated for strip footing using the numerical results in two different approaches: 1) using ultimate unit bearing pressure, and 2) using the peak load. The stress scale ratio was calculated to be 17.0 using ultimate unit bearing pressure and 16.3 using peak load. As the proposed stress scale ratio was obtained for just one case with certain material parameters, the ratio should not be directly applied without validation. The ratio should be modified and validated through further numerical analyses or experimental tests.

Fig. 5 shows the unit bearing pressure - settlement curve after applying geometric scale ratio to the settlement and stress scale ratio to the ultimate bearing pressure. It is very interesting to note that the geometric scale ratio does not work well for the settlement conversion in spite of widely accepted unproven rule. The strip footing in full scale settles more by $75 \%$ than laboratory test. The discrepancy is likely due to the variation of elastic modulus with depth, which is not accounted for the geometric scale ratio. It appears that the scaling factor to the settlement should be used with caution. 


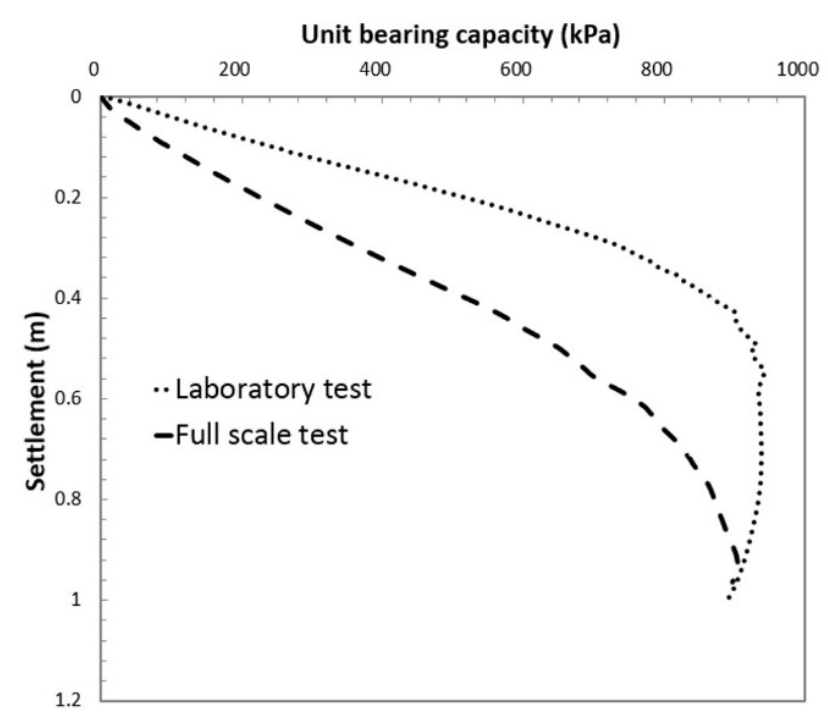

Fig. 5 Unit bearing pressure - settlement curve for laboratory test and full scale test

\section{CONCLUSIONS}

In this study, scaling relation for strip footing among laboratory model test, centrifuge test, and full sale test were investigated using 2D finite element method. The unit bearing pressure - settlement curves were obtained from numerical analyses, and the geometric scale ratio and stress scale ratio were back-calculated. Based on the numerical results, following conclusions were drawn:

1) The centrifuge test results agree well with the full scale tests using geometric scale ratio, $n$; the discrepancy was estimated to be $4.7 \%$ for ultimate unit bearing pressure, and negligible for settlement

2) The stress scale ratio, $N$, was back-calculated to be 16.3 for unit bearing pressure and 17.0 for peak load. The stress scale ratio could be used to convert the bearing pressure of strip footing measured in the laboratory model test to that of full scale test.

3) The geometric scale ratio, $n$, appears to be inappropriate when converting the settlement of laboratory model test to full scale test. The full scale strip footing was found to settle $75 \%$ more than laboratory model. The discrepancy may be due to the variation of elastic modulus with depth, which was not considered in scaling relation.

\section{ACKNOWLEDGEMENT}

This work was supported by National Research Foundation of Korea (NRF) funded by Ministry of Science, ICT \& Future Planning (NRF- 2013R1A1A1011983)
1) Brinkgreve, R. B. J. (2002): User's manual for PLAXIS 2D-version 8, Balkema, Rotterdam, Netherlands.

2) Ko, H. Y. (1988): Summary of the state-of-the-art in centrifuge model testing. Centrifuges in soil mechanics, pp. 11-18.

3) Mandal, J.N., and Manjunath, V.R. (1995): Bearing capacity of strip footing resting on reinforced sand subgrades, Construction and Building Material, 9(1), pp. 35-38.

4) Meyerhof, G.G. (1951): The ultimate bearing capacity of foundations. Geotechnique, 2(4): pp. 301-302.

5) Terzaghi, K. (1943): Theoretical soil mechanics, John Wiley \& Sons, New York.

\section{REFERENCES}

